\title{
Pseudophakic Angle Closure Due to Vitreous Block Following Ureteroscopic Lithotripsy
}

This article was published in the following Dove Press journal:

International Medical Case Reports Journal

\section{Purit Petpiroon \\ Yanin Suwan (D) \\ Chaiwat Teekhasaenee \\ Wasu Supakontanasan}

Department of Ophthalmology, Faculty of Medicine, Ramathibodi Hospital, Mahidol University, Bangkok, Thailand
Correspondence: Yanin Suwan

Department of Ophthalmology, Faculty of Medicine, Ramathibodi Hospital, Mahidol

University, Bangkok, Thailand

Tel +66 2-20l-2729

Fax +66 2-354-7280

Email yanin.suwan@gmail.com
Background: Here, we describe a patient who exhibited pseudophakic angle closure due to vitreous block following ureteroscopic lithotripsy under general anesthesia.

Case Presentation: A 57-year-old Thai man presented with sudden eye pain and blurring of vision in the left eye following ureteroscopic lithotripsy under general anesthesia. The patient had a history of coconut hit into his left eye which resulted in traumatic anterior lens subluxation, for which he had undergone phacoemulsification and scleral-fixated intraocular lens implantation in the left eye. Prior scleral fixation procedure, anterior vitrectomy was not performed. Clinical examination showed mushroom-shaped vitreous in the anterior chamber with absolute pupillary block, which had resulted in acute angle closure. Thus, topical and oral antiglaucoma medications were administered to achieve normal intraocular pressure in the left eye, followed by laser peripheral iridotomy in that eye. The anterior chamber depth was successfully increased. Limited anterior vitrectomy by a pars plana approach was performed to prevent recurrent angle closure. The patient's vision improved and his intraocular pressure remained controlled without any antiglaucoma medication.

Conclusion: Vitreous block can occur in patients with pseudophakia, especially in the presence of a ruptured posterior capsule. Cautious intraoperative anterior vitrectomy and surgical iridectomy are warranted. General anesthesia may contribute to the onset of vitreous block in susceptible patients.

Keywords: acute angle closure, pseudophakic angle closure, vitreous block, ultrasound biomicroscopy, anterior segment optical coherence tomography

\section{Introduction}

Acute angle closure is less common in patients with pseudophakia, compared with patients with phakia; this type of closure can have various causes. ${ }^{1}$ The underlying mechanism can involve force originating at the level of the iris; examples include absolute pupillary block due to iris-intraocular lens contact (eg, during anterior chamber intraocular lens implantation), iris-air contact, iris-silicone oil contact, iris-residual posterior capsule contact, iris-postoperative membrane contact, and iris-vitreous contact. In addition to pupillary block, angle closure in patients with pseudophakia can also result from factors such as Soemmering ring, ${ }^{2}$ ciliochoroidal detachment, and malignant glaucoma. ${ }^{3}$ Here, we describe a patient who exhibited pseudophakic angle closure due to vitreous block following ureteroscopic lithotripsy under general anesthesia.

\section{Case Report}

A 57-year-old Thai man presented with sudden eye pain and blurring of vision in the left eye. The patient had a history of traumatic anterior lens subluxation four years 
prior, for which he had undergone phacoemulsification and scleral-fixated intraocular lens implantation in the left eye. A few hours prior to onset of his symptoms, he had undergone ureteroscopic lithotripsy under general anesthesia. During the operation, the patient was placed in a lithotomy position. Eight hundred milliliters of isotonic saline were used during the operation. Both intravenous anesthetic agents and inhaled anesthetic agents were used during the procedure (ie, propofol, atropine, nitrous oxide, and sevoflurane).

Upon presentation in our clinic, the patient's bestcorrected visual acuity was 20/70 in the right eye and 20/ 200 in the left eye. His IOP was $12 \mathrm{mmHg}$ in the right eye and $57 \mathrm{mmHg}$ in the left eye. Slit-lamp biomicroscopy examination showed ciliary injection and generalized bedewing of the cornea in the left eye. Grade 1-shallow anterior chamber and protrusion of the anterior hyaloid membrane were noted (Figure 1). The vitreous was pushed forward by pressure that originated from behind the iris, resulting in vitreous-corneal apposition. The scleral-fixated intraocular lens was pushed backward into an abnormally posterior position. Slit-lamp biomicroscopy findings in the right eye were unremarkable. The anterior chamber in the right eye was deep with a posterior chamber intraocular lens; one year prior, the patient had undergone uneventful phacoemulsification in the right eye. Cup to disc ratios were 0.3 in both eyes. Gonioscopy revealed 360-degree angle closure in the left eye. The patient then underwent ultrasound biomicroscopy. The findings demonstrated asymmetrical pupillary block in the left eye, with an obviously shallow anterior chamber. The scleral-fixated intraocular lens was pushed away from the iris plane (Figure 2). However, vitreous mass could not be determined by ultrasound biomicroscopy

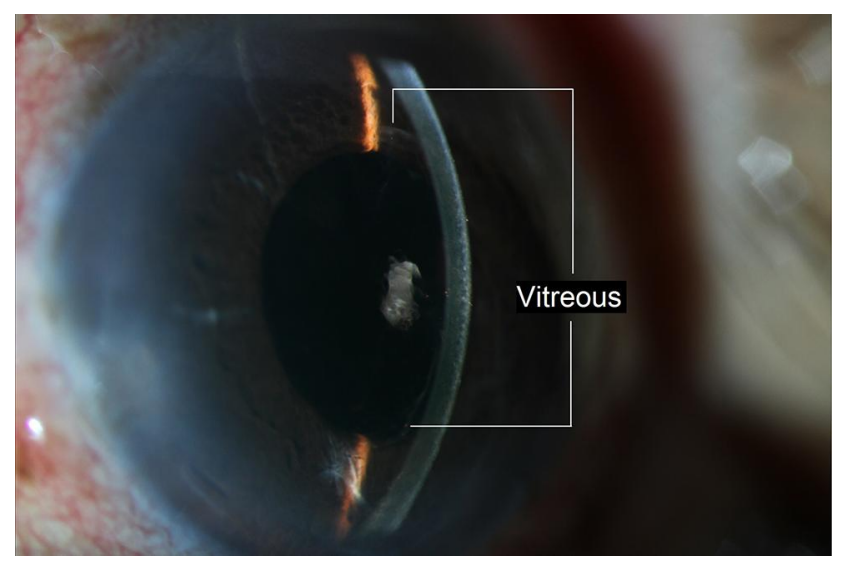

Figure I Anterior segment photograph demonstrated vitreous protrusion into anterior chamber.

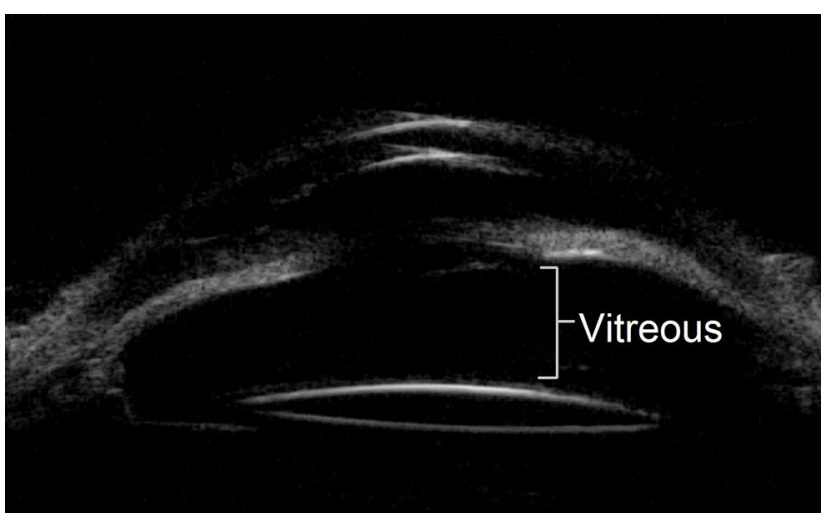

Figure 2 Ultrasound biomicroscopy (UBM) showed shallow anterior chamber with abnormal position of scleral-fixated intraocular lens.

because of poor resolution. Pentacam imaging revealed a vitreous mass in the anterior chamber, which appeared as a faint curvilinear line around the mid-iris zone.

The patient was treated with two topical antiglaucoma medications and oral acetazolamide for reduction of IOP. Following normalization of IOP and clearing of the cornea, laser iridotomy was performed in the patient's left eye. The anterior chamber underwent a dramatic change to the normal deep configuration following treatment with laser peripheral iridotomy. The vitreous-corneal apposition no longer persisted and the iris returned to a flat configuration. Subsequent anterior segment optical coherence tomography showed a clear relationship among the vitreous, cornea, and iris (Figure 3). Four weeks after the acute angle closure event, the patient underwent anterior vitrectomy using a pars plana approach in the left eye; this removed the vitreous and was expected to prevent recurrent vitreous block-induced angle closure. The patient's vision returned to normal (bestcorrected visual acuity of 20/20) in the left eye. The IOP remained at approximately $10-15 \mathrm{mmHg}$ without any antiglaucoma medication. Gonioscopy revealed a normal open angle without any residual peripheral anterior synechia.

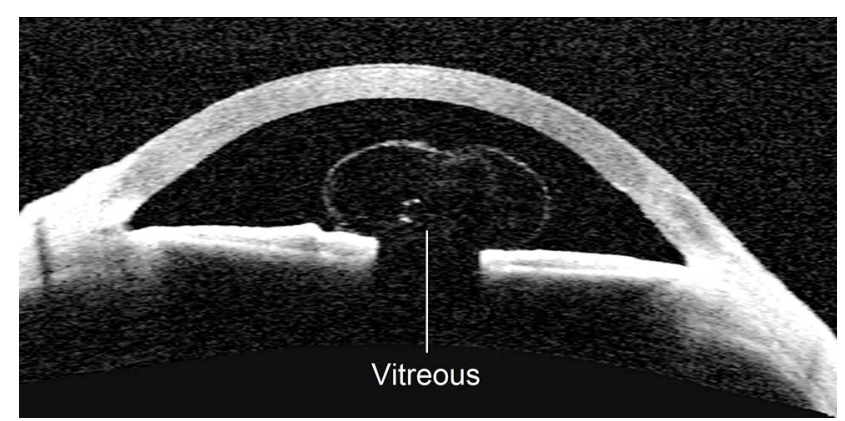

Figure 3 Anterior segment optical coherence tomography showed mushroomshaped vitreous after laser peripheral iridotomy. 


\section{Discussion}

Our patient presented with acute angle closure in the left eye, a few hours after a ureteroscopic procedure. The patient had a notable risk factor: vitreous prolapse due to prior trauma with inadequate vitrectomy. Certain actions such as the Valsalva maneuver are presumed to increase IOP and may facilitate vitreous movement from the posterior segment to the anterior segment in patients with a ruptured anterior hyaloid membrane. ${ }^{4}$ Both intubation and extubation can trigger the gag reflex and severe coughing, which increase intrathoracic pressure and IOP. ${ }^{5}$ Some types of anesthetic agents and depths of anesthesia may also interfere with pupillary size, ${ }^{6}$ thereby facilitating iris-vitreous blockage. Furthermore, in some stages of anesthesia, a mydriatic pupil may allow the vitreous to move from the posterior segment to the pupillary plane, which results in vitreous block during return to the normal pupillary size condition. The lithotomy position might not have affected the occurrence of angle closure in our patient because his head and body were at the same level. However, the lithotomy position can increase venous return, thereby increasing cardiac output. The clinical manifestation in this patient was acute angle closure due to an abrupt increase in IOP. Slit-lamp biomicroscopy revealed absolute pupillary block. Ancillary assessment by ultrasound biomicroscopy confirmed vitreous-induced pupillary block. Initial management comprised reduction of pressure to limit optic nerve damage, using topical and oral aqueous suppressants. Subsequently, laser peripheral iridotomy was performed to eliminate angle closure at the pupillary plane. In our patient, angle closure mainly occurred at the pupillary plane, but was not due to the mass effect of the vitreous behind the iris. Therefore, this event was completely resolved by laser peripheral iridotomy. However, definite treatment with anterior vitrectomy should be performed when possible because vitreous behind the iris can cause recurrent blockage if it occludes the laser peripheral iridotomy and pupil simultaneously.

\section{Conclusion}

Vitreous block can occur in patients with pseudophakia, especially in the presence of a ruptured posterior capsule.
General anesthesia may contribute to the onset of vitreous block in susceptible patients.

\section{Consent}

Written informed consent was obtained from the patient for publication of this case report and any accompanying images. The Institutional Review Board, Faculty of Medicine, Ramathibodi hospital granted approval to publish the case details.

\section{Author Contributions}

All authors made substantial contributions to conception and design, acquisition of data, or analysis and interpretation of data; took part in drafting the article or revising it critically for important intellectual content; agreed to submit to the current journal; gave final approval of the version to be published; and agree to be accountable for all aspects of the work.

\section{Funding}

There is no funding to report.

\section{Disclosure}

The authors report no conflicts of interest in this work.

\section{References}

1. Tomey KF, Traverso CE. The glaucomas in aphakia and pseudophakia. Surv Ophthalmol. 1991;36(2):79-112. doi:10.1016/0039-6257(91) 90124-X

2. Suwan Y, Purevdorj B, Teekhasaenee C, Supakontanasan W, Simaroj P. Pseudophakic angle-closure from a Soemmering ring. BMC Ophthalmol. 2016;16:91. doi:10.1186/s12886-016-0257-6

3. Kaplowitz K, Yung E, Flynn R, Tsai JC. Current concepts in the treatment of vitreous block, also known as aqueous misdirection. Surv Ophthalmol. 2015;60(3):229-241. doi:10.1016/j.survophthal.20 14.12.004

4. Kim YW, Park KH. Exogenous influences on intraocular pressure. $\mathrm{Br}$ $J$ Ophthalmol. 2019;103(9):1209-1216. doi:10.1136/bjophthalmol2018-313381

5. Barclay K, Wall $\mathrm{T}$, Wareham $\mathrm{K}$, Asai $\mathrm{T}$. Intra-ocular pressure changes in patients with glaucoma. Comparison between the laryngeal mask airway and tracheal tube. Anaesthesia. 1994;49 (2):159-162. doi:10.1111/j.1365-2044.1994.tb03378.x

6. Sabourdin N, Meniolle F, Chemam S, et al. Effect of different concentrations of propofol used as a sole anesthetic on pupillary diameter: a randomized trial. Anesth Analg. 2020;131(2):510-515. doi:10.1213/ANE.0000000000004362 


\section{Publish your work in this journal}

The International Medical Case Reports Journal is an international, peer-reviewed open-access journal publishing original case reports from all medical specialties. Previously unpublished medical posters are also accepted relating to any area of clinical or preclinical science. Submissions should not normally exceed 2,000 words or 4 published pages including figures, diagrams and references. The manuscript management system is completely online and includes a very quick and fair peer-review system, which is all easy to use. Visit http://www.dovepress.com/testimonials.php to read real quotes from published authors. 